\title{
The distribution of mental health services within NHS trusts
}

\author{
Judy Harrison
}

\begin{abstract}
From April 1994, over $95 \%$ of health care services will be provided by NHS truets. Mental Heatth services hove a cholce of remaining within the acute hoeplital trust or forming part or all of a community frust. Using data from trust directories, the distribution of mental health services within the first three trust waves is described. Forty per cent of acute hoeplital trusts currentty do not include mental heath services. Unilike other specialities, a signilicant proportion of mental health services are choosing to form speciallist mental health trusts. The implications of the altemative trust arrangements for peychiatiny are cliscuseed.
\end{abstract}

One key aspect of recent managerial changes in the health service has been the introduction of NHS trusts (NHS and Community Care Act, 1990). These are "hospitals and other units run by their own Board of Directors; independent of district and regional management; with wide ranging freedoms not available to units which remain under health authority control" (NHS Trusts: a working gutde, 1990). Four 'waves' have now been established and it is estimated that from April 1994, 95\% of health care services will be delivered by NHS trusts.

Although some trusts contain all the elements of service provision previously managed by one health authority (the whole district trust), increasingly it seems that services are being divided into acute and community trusts. Particularly for psychiatry this poses a difficult choice between remaining part of the acute hospital services or forming part or all of a community trust.

Such a decision has major implications for the delivery of mental health services, but there has been little debate about the advantages and disadvantages of the various options. This paper uses data currently avallable only in trust directories to summarise the current status of psychiatry within NHS trusts and to consider the implications for future mental health services.

\section{The study \\ Types of trust}

The data were derived from two sources: the Newchurch Guide to NHS trusts (1993) and the Directory of Hospitals and NHS trusts (1993). The data in these directories were collated in early 1993 (further changes may have occurred since then, particularly relating to services in the London area). Existing trusts were assigned to one of seven categories: predominantly acute services, predominantly community services, mixed acute and community services, specialist mental health services, specialist learning disability services, ambulance services and other specialist services. While the first wave of trusts was dominated by acute or mixed trusts, the second and third wave included more community orientated trusts and a more even spread of trusts between the three largest categories (Table 1). Comparing these three trust categories only, there is a significant shift towards community orientated trusts in the second and third waves $\left(\chi^{2}=12.5, P=0.01\right)$. ( $P=0.0137$ exactly).

In total, 14 trusts contain mental health services only and a further 12 are specialist learning disability trusts. Detailed information on the composition of fourth wave trusts was not avallable at the time of writing but of the 119 services becoming trusts from April 1994. It was clear from their titles that at least nine (7.6\%) are specialist mental health trusts. This trend towards specialist trusts is not seen in other medical specialities, with a total of only 16 other specialist trusts (excluding ambulance services) spread across several disciplines.

\section{Location of mental health services}

Excluding specialist trusts, mental health services appear to be fairly equally distributed between the three main types of trust, with 73 (40\%) within acute hospital trusts, 52 (28\%) within mixed acute and community trusts and 58 (32\%) within community trusts (Table 2). Of the 121 acute trusts, $48(40 \%)$ do not appear to contain mental health services, while the corresponding figures for community trusts and mixed acute and community trusts are $27 \%$ and $13 \%$ respectively $\left(\chi^{2}=13.8, P<0.001\right)(P=0.00098$ exactly). 
Table 1. Trust type by wave

\begin{tabular}{lccc}
\hline & Ist wave & 2nd wave & 3rd wave \\
\hline & $\%$ & $\%$ & $\%$ \\
Mainly acute & $21(37)$ & $39(37)$ & $62(37)$ \\
Mainly community & $5(9)$ & $32(30)$ & $42(25)$ \\
Mixed acute and community & $15(26)$ & $12(11)$ & $33(20)$ \\
Specialist mental illness & $4(7)$ & $3(3)$ & $7(4)$ \\
Specialist learning disability & $2(3)$ & $5(5)$ & $5(3)$ \\
Specialist other* & $7(12)$ & $7(7)$ & $2(1)$ \\
Ambulance & $3(5)$ & $7(7)$ & $16(10)$ \\
Total & 57 & 105 & 167 \\
\hline
\end{tabular}

*Includes 3 cardiac, 3 oncology, 2 childrens, 2 orthopaedic, 2 rheumatology, 1 neurology, 1 ENT, 1 homeopathic and 1 obstetric service.

Table 2. Mental health services by trust type (acute and community trusts)

\begin{tabular}{lcc}
\hline & \multicolumn{2}{l}{ Mental health services included } \\
\cline { 2 - 3 } & Yes & No \\
\hline & $\%$ & $\%$ \\
Mainly acute trust & $73(60)$ & $48(40)$ \\
Mainly community trust & $58(73)$ & $21(27)$ \\
Mixed acute and community & $52(87)$ & $8(13)$ \\
Total & $183(70)$ & $77(30)$ \\
\hline
\end{tabular}

$\chi^{2}=13.8, P<0.001 \quad(P=0.00098)$

\section{Implications for psychiatry}

\section{Mixed acute and community trusts}

Mixed acute and community trusts represent the option of least change since all aspects of a service remain within the same managerial structure. Such continuity of care as previously existed is therefore likely to be preserved. However, at least in London, this option was criticised by the Tomlinson Inquiry (1992) on two counts. First, there is a continuing tendency for resources to be drawn away from the community aspects of such trusts, such as mental health, towards the acute sector. Second, the lack of distinction between acute and community services does little to focus the attention of the provider on specific services or to help purchasers re-examine priorities and place contracts in new ways. Perhaps as a result of such criticisms, the emphasis from central government has been to move away from the concept of the whole district trust.

\section{Acute hospital trusts}

People with mental illness need a service which can offer treatment in a variety of settings at the same time maintaining continuity of care. Even if psychiatrists choose to form part of an acute hospital trust, other members of the multi- disciplinary team, including community psychiatric nurses, occupational therapists and psychologists, may move into the community trust. As a result, continuity of care and co-ordination between mental health workers will suffer.

Divisions may also occur within the consultant staff, with those working in specialities such as learning disabilities and child and adolescent psychiatry moving into the community trust, while general adult psychiatrists remain in the acute hospital trust. In the short term such changes may seem relatively unimportant, but as trusts set new objectives, modify existing managerial practices and change conditions of employment the gap between mental health workers in different trusts is likely to widen.

\section{Community trusts}

In order to retain all mental health workers within the same organisational structure, many services have elected to become part of a community trust. This consolidates the existing trend towards community orientated mental health services and facilitates the development of links with primary care (Griffiths, 1992). In some areas, for example City and East London, such developments have been taken further by the organisational merger of existing community health services, including mental health, with 
the Family Health Services Authority (CELFACS, 1993).

Since community trusts are generally smaller than acute hospital trusts, they may offer a greater degree of financial and managerial autonomy. Mental health may form the largest clinical directorate and psychiatrists are well placed to act as medical directors for community trusts. This has important implications when competing for budgets, negotiating with purchasers and interacting with executive and nonexecutive directors. However, there may be some drawbacks. Relationships with senior managers are likely to assume more critical dimensions, while smaller budgets may be more vulnerable to the whims of the market. In addition although community trusts may be philosophically in tune with other developments in mental health, they present a number of difficulties for psychiatrists. Foremost among these is the gradual erosion of links with the general hospital (Weich, 1994).

In spite of research showing high levels of psychological morbidity in the physically ill (Mayou \& Hawton, 1986), the data presented suggest that $40 \%$ of acute hospital trusts do not currently include mental health services. Liaison psychiatry services have been shown to be cost effective (Hammer, 1990) but they remain in their infancy in many places, and there is a danger that managers of acute hospital trusts will see no need to contract for such services. The Directory of Trusts suggests that in a handful of cases acute trusts are electing to employ a liaison psychiatrist and this model could be usefully adopted elsewhere.

It is only in recent years, with the movement of psychiatrists into district general hospitals, that psychiatry has achieved the status it deserves as a medical speciality. This is in part due to the closer professional and social contact with colleagues in other specialities developed as a result of sharing location and employer. Although it is difficult to quantify, closer collaboration with medical colleagues is likely to result in a greater understanding of the interplay between physical and psychological health on both sides. If psychiatrists retreat from the general hospital, such benefits may be lost.

Community trusts would also need to negotiate separate access to other acute services, such as medical consultation, diagnostic tests and research and teaching facilities.

\section{Specialist mental health trusts}

The advantages of forming a specialist mental health trust are likely to be an extension of those experienced by generic community trusts, in particular, greater financial and managerial autonomy. The move to provide specialist services of this kind does not, however, appear to be occurring in other medical specialties, except where previously regional or supra-regional service existed. The reasons for this are speculative but perhaps reflect increasing frustration among mental health professionals with the perceived underfunding of their services.

Many of the specialist mental health trusts appear to represent mergers between a number of traditional district services to provide, for example, a city-wide mental health service. A minimum size for trusts has not been established but there is presumably a critical mass of providers below which the formation of a trust would not be worthwhile. Small mental health trusts may be isolated from other health services and more vulnerable to market forces.

\section{Conclusions}

As anticipated, the data presented suggest that psychiatrists are adopting a variety of managerial structures within NHS trusts. The advantages and disadvantages of the different trust structures have received little attention, in spite of their implications for the role of psychiatrists and the future of mental health services. Although many services have already taken the decision about trust status, those few services which have not yet done so may benefit from the experience of psychiatrists in existing trusts. Other services may wish to review their organisational structure in the light of wider debate. The development of specialist mental health trusts is of particular interest as it may provide an organisational structure within which psychiatrists command more influence over their own destiny.

\section{References}

CELFACS (1994) City and East London Family and Community Health Services: options for the future. Discussion Paper.

Directory of Hospitals and NHS Trusts 1993/4 (1993) London: Churchill Livingstone.

GRIFFITHS. S. (1992) Community unit trusts. British Journal of Hospital Medicine, 47, 493-494.

HAMMER, J.S. (1990) The cost-benefit of psychiatric consultation liaison services in the medical setting. Current Opinion in Psychiatry. 3, 687-691.

MAYOU, R. \& HAWTON, K. (1986) Psychiatric disorder in the general hospital. British Journal of Psychtatry. 149, 172190.

NHS Trusts: a working guide (1990) London: HMSO.

The 3rd Newchurch Guide to NHS Trusts (1993) London: Newchurch \& Co.

The NHS and Community Care Act (1990) London: HMSO.

TOMLINSON. B. (1992) Report of the Inquiry into London's Health Service, Medical Education and Research. London HMSO.

WEICH. S. (1994) NHS trusts: recent government policy and legislation. Psychiatric Bulletin, 18, 131-134.

Judy Harrison, Lecturer in Community Psychiatry. Department of Academic Psychiatry, Royal Preston Hospital, Sharoe Green Lane, Preston PR2 4HT 